\title{
STRUCTURAL EVALUATION AND MAINTENANCE OF GREENHILL MINE TIPPLE STRUCTURE HISTORIC SITE
}

\author{
ALIREZA ROUHI ${ }^{1}$, NIGEL G. SHRIVE ${ }^{2 *}$ \\ ${ }^{1 \& 2}$ University of Calgary, Schulich School of Engineering \\ 622 Collegiate P1 NW, Calgary, AB, CANADA T2N 4V8 \\ e-mail: alireza.rouhi@ucalgary.ca, \\ email: ngshrive@ucalgary.ca, www.ucalgary.ca (*corresponding author)
}

Keywords: Reinforced Concrete, Mine Tipple, Structural Evaluation, Durability, Damage, Numerical Modeling,

\begin{abstract}
The tipple building located within the Greenhill Mine complex (a Provincial historic site) in southern Alberta, Canada is a reinforced concrete frame with a steel superstructure. The structure has been analyzed to assess its current state and the extent and causes of deterioration. The analysis is performed using data obtained from field and laboratory tests and evaluations and by using SAP2000 structural analysis software. Possible ways for conservation and restoration of the building for two different future uses are explored, and recommendations are provided.
\end{abstract}

\section{INTRODUCTION}

The Greenhill mine primary rotary tipple structure is a part of the mining complex located in the Crowsnest Pass area of southern Alberta, Canada and is the most important building at the site. The structure consists of a 40-metre-long, 9-metres wide concrete frame supporting a steel superstructure. This type of construction was quite innovative and was considered stateof-the-art at the time of its development in 1914 because of using new methods and materials such as steel and reinforced concrete. Various types of damage and deterioration are visible on the tipple structure. The causes and extent of these deteriorations are examined and possible methods for repair and conservation of the structure are discussed.

\section{HISTORY AND SIGNIFICANCE}

Coal mining was the main part of the economy of the Crowsnest Pass area of southwest Alberta during the first half of the 20th century. The historic Greenhill Mine Complex was one of a series of active coal mining operations in the Crowsnest Pass area, being a significant part of the industry. The complex is located north of Highway 3 next to the town of Blairmore. The mine began service in 1914, operated by West Canadian Collieries. Like other mining communities in the area, the mine suffered from rapid changes in coal prices during its time of operation. With the introduction of diesel engines by the Canadian Pacific Railway Company (CPR) in the early 1950s, the mining operations at Greenhill ceased in 1957, and the site was abandoned [1]. An overall view of the tipple building is shown in Figure 1. 
In the 1980s, in recognition of the significance of coal mining to the surrounding communities culturally and economically in the first half of the twentieth century, the Greenhill Mine Complex was designated as a Registered Historical Resource. It is now under the care and control of the Government of the Province of Alberta.

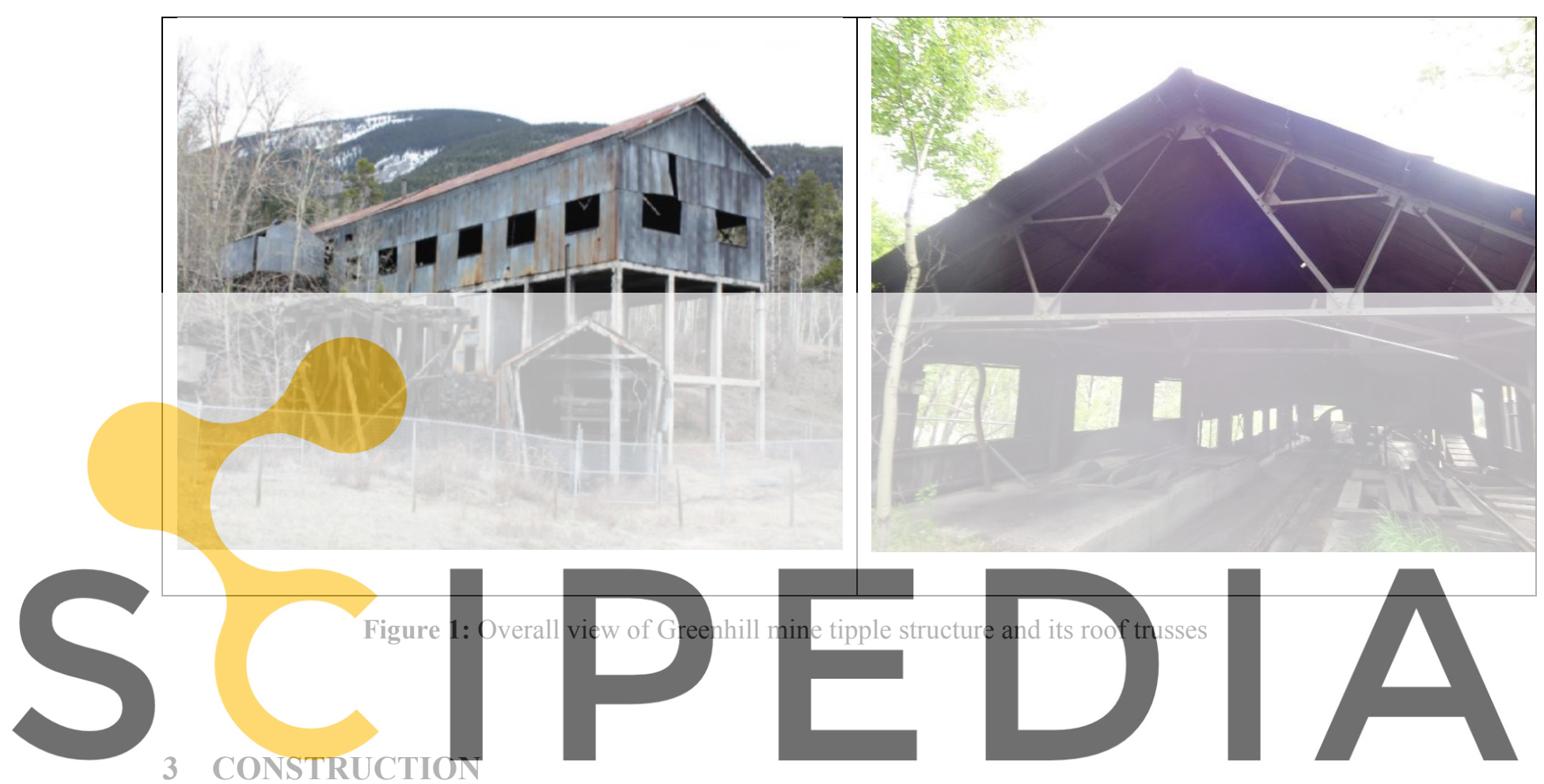

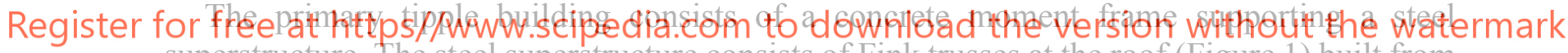
superstructure. The steel superstructure consists of Fink trusses at the roof (Figure 1) built from double angle chords, single angle web members, and channel purlins.

The columns of the steel superstructure are built-up members of channels and angles. Single angle braces located at two bays on each side of the building provide lateral load resistance in the longitudinal direction. Some parts of the braces, as well as some steel elements of the roof trusses, have been removed at some unrecorded time in the past (for example Figure 2). No lateral load supporting system exists in the short direction of the superstructure and it is not clear if any bracings existed originally in that direction, as there are no records of design, construction, alterations or maintenance. As a result, only moment frame action of the steel columns provides lateral resistance in the short direction. Thus, additional bracings have to be provided in the short direction to ensure the stability of the superstructure. This issue is discussed later.

The steel superstructure was built on a $200 \mathrm{~mm}$-thick concrete slab, which is supported on an exposed concrete frame with $300 \mathrm{~mm}$ square concrete columns and beams. The beams and columns are each reinforced with at least four round rebars of $20 \mathrm{~mm}$ diameter. Bars of different dimensions and sections were used with inadequate lap splicing (for example, see Figure 3). 


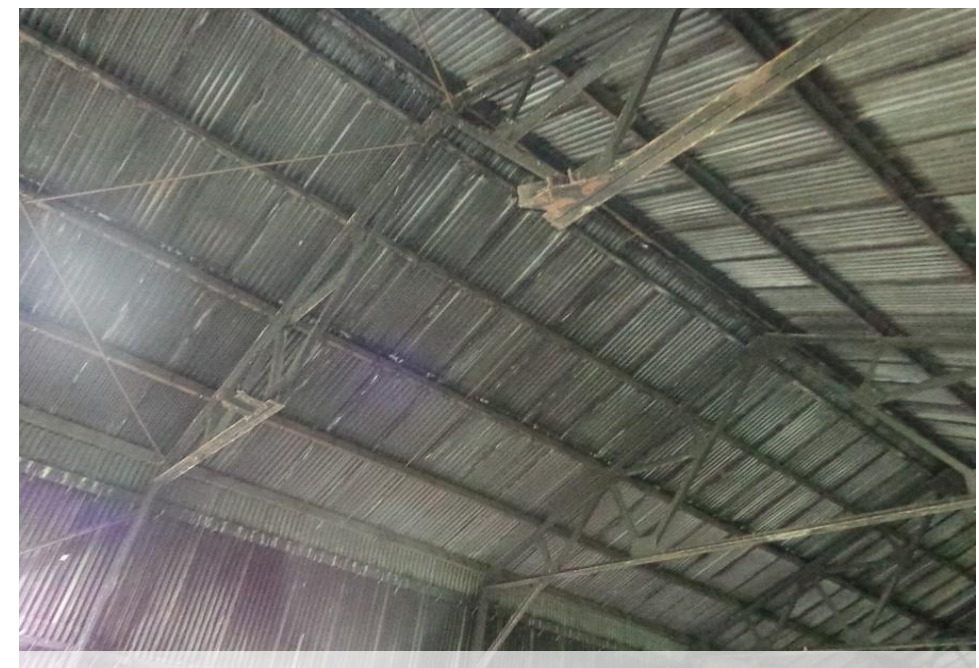

Figure 2: Roof truss with part of the bottom chord removed
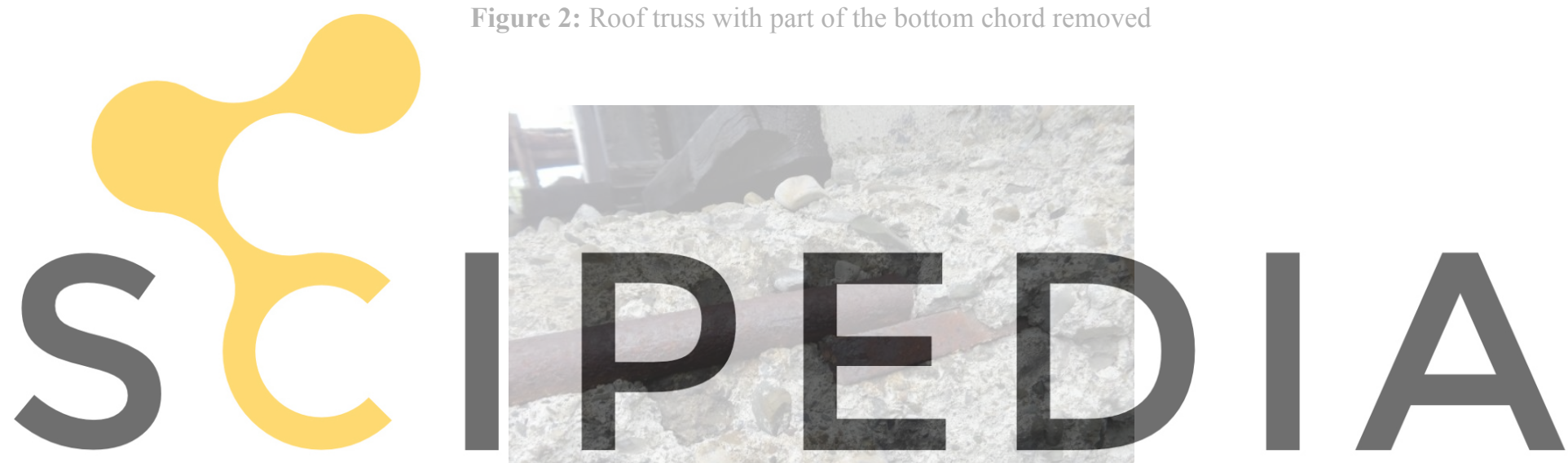

Register for free at https//www.scipedia.com to download the version without the watermark

Figure 3: A round bar overlapped with a square bai in a splice. Also note variation in aggregate size and shape

\subsection{PREVIOUS CONDITION ASSESSMENTS}

A visual condition assessment of the primary tipple was conducted in 2013 [1]. Based on the results of structural evaluation of the tipple building structure, the following types of deterioration and damage and their respective areas were detected and listed based on the severity of damage from most to least important [1]:

1- Section loss and spalling due to freeze-thaw in concrete columns

2- Removed members in the steel superstructure

3- Section loss and spalling due to freeze-thaw in concrete beams

Some signs of damage and deteriorations are shown in Figure 4. 


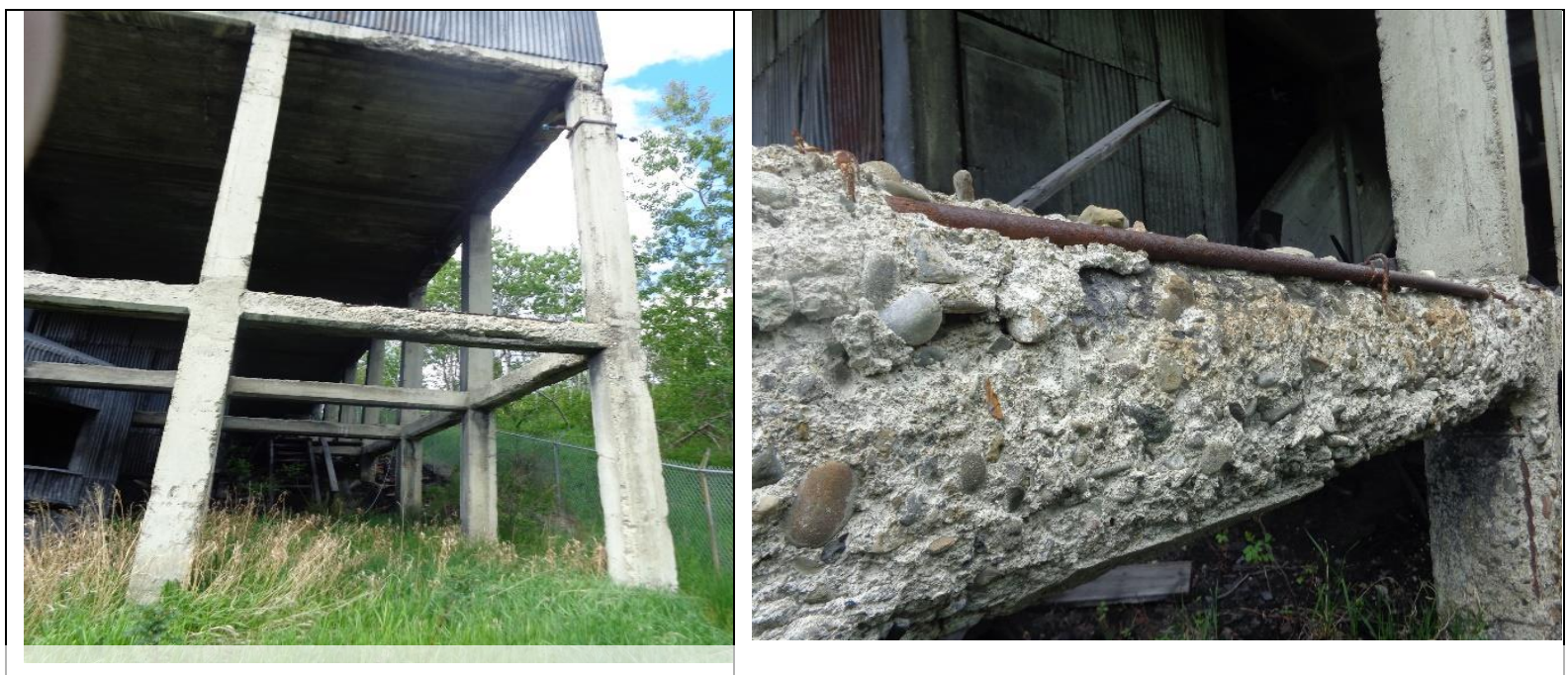

Figure 4: Signs of deterioration on concrete members

\subsection{CONCRETE TEST AND SAMPLING}

To investigate the condition of the structure further, field sampling was performed (Figure 5). To avoid inclusion of steel reinforcement in the concrete samples as well as to identify the location of rebars in the concrete for further analysis, a ground-penetrating radar scan device

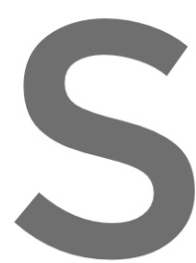
called "structure scan" was used during the sampling process (Figure 6). "Structure scan" manufactured by GSSI (a menber of the OYO group) and can find the location, depth, and s of reinforcing bars as deep as $500 \mathrm{~mm}$. The existence of large size aggregate particles in the concrete caused some difficulties strch as the failure of several cores during the sampling process. Fourteen concrete cylinder cores were obtained. Six cores had diameter of $95 \mathrm{~mm}$ (3.75 inches), and eight had a diameter of $70 \mathrm{~mm}$ ( 2.75 inches). The core samples were cut wet

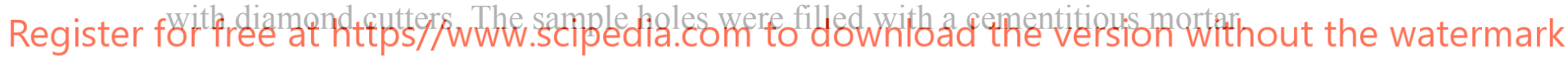

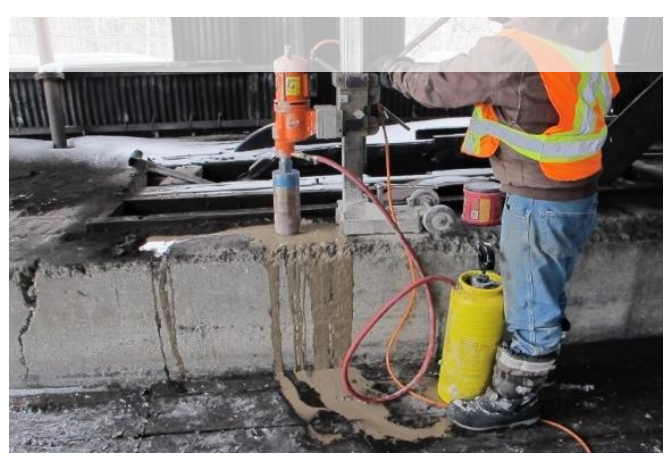

Figure 5: Concrete sampling 


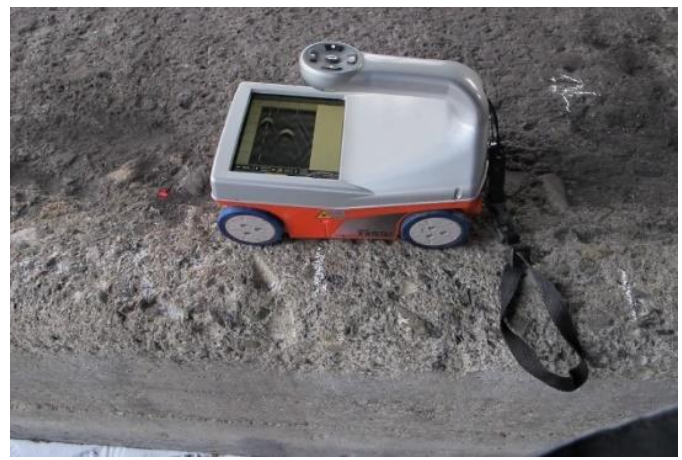

Figure 6: Ground-penetrating radar scan

\subsection{CONCRETE PROPERTIES}

In the absence of any construction documents and drawings, visual inspection of the concrete material revealed some useful information about the properties of the material used in the concrete. The aggregates used in the concrete include a very broad range of size and shape, including some large aggregate particles more than $100 \mathrm{~mm}$ in the largest dimension (Figure 7 and Figure 3). One may surmise that the contractor used gravel obtained directly from the river nearby as there appears to be no grading of the aggregate.

Three core samples were tested to obtain the compressive strength of the concrete. Samples were prepared for the compressive testing by cutting the ends with a 20 " masonry saw The ends were then glycapped (Figure 7), and the samples tested aceording to ASTM C-39.

The compressive strengths obtained from the three core samples were 12.1, 23.4 and $\mathrm{MPa}$, so the equivalent compressive strength of the concrete for the Grgenhill inir based on ACI standard 562-16 (Code requirements for assessment, repair, and reha existing concrete structures) was calculated to be $15 \mathrm{MPa}[2]$

concrete compressive strength in the analysis and strengthening of the structure. The average

Register fopafreansity

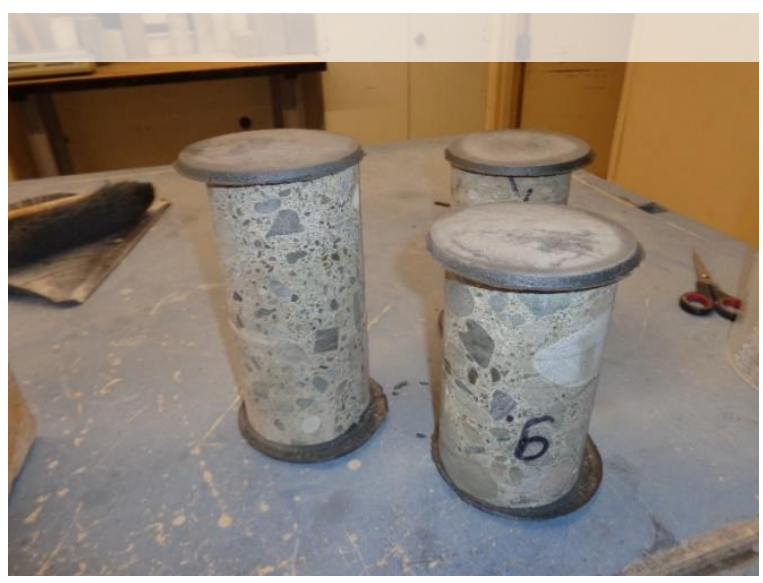

Figure 7: Preparation of samples for compressive test. Note the large aggregates in the samples

\subsection{REINFORCEMENT STEEL PROPERTIES}

ACI 562-16 [2] suggests using default strengths for structural steel based on their 
construction time frames. Based on the time of construction of the tipple building (around 1914) and in the absence of construction documents and data from tests, the minimum yield strength of structural steel reinforcing bars is considered to be $227 \mathrm{MPa}$ (33000 psi) [2].

\section{STRUCTURAL MODEL OF THE BUILDING}

Analytical models of the tipple structure were made in SAP2000 software version 19.0 for two future use scenarios:

1- Adaptive re-use of the building as a restaurant

2- Utilizing the structure in the current loading condition with occasional visitors

The geometry of the model was obtained from existing recently created as-built drawings and additional site measurements. The load cases and combinations were obtained from "National Building Code of Canada (NBCC-2015)" [3]. Load cases are defined as follows:

D: Dead load (including self-weight of the structure + superimposed dead load)

L: Live Load (if structure to be developed into a restaurant)

S: Snow Load

W: Wind Load

For the case of adaptive reuse as a restaurant, a live load of $4.8 \mathrm{kPa}$ and superimposed dead load of $1 \mathrm{kPa}$ in the main floor were considered based on NBCC 2015. The missing steel members of roof truss were replaced, and steel bracings added in both directions of the building to ensure the stability of the steel superstructure. Figure 8 shows the structure modelled.
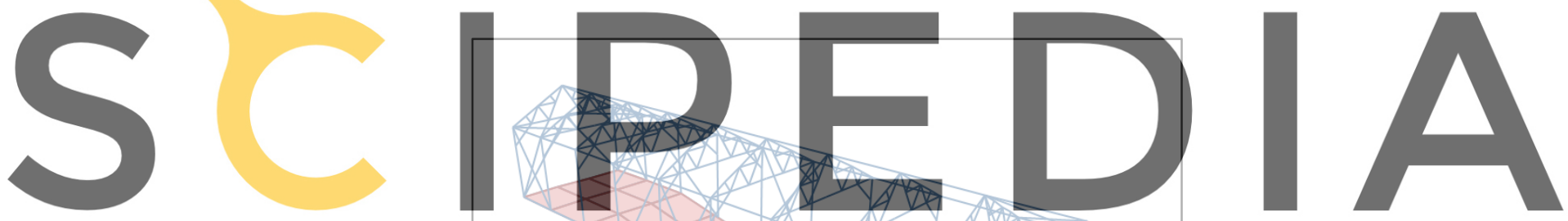

Register for free at https//www.scipedia.com to download the Nersion without the watermark

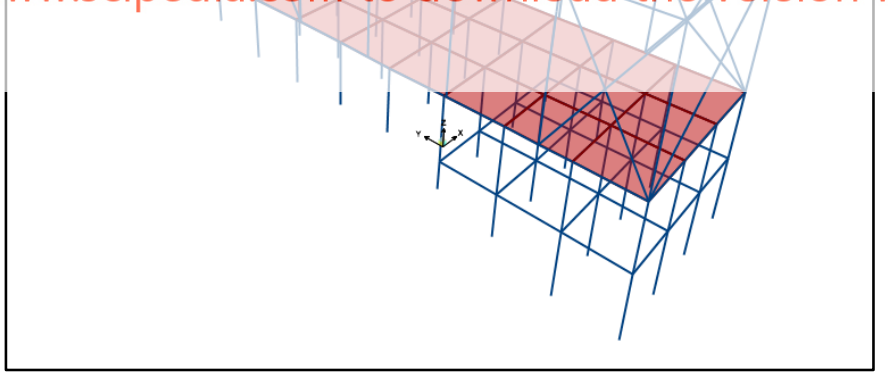

Figure 8: The structural model of Greenhill building in SAP2000

\subsection{STRUCTURAL EVALUATION BASED ON ADAPTIVE REUSE AS A RESTAURANT (SCENARIO 1)}

The main purpose was to evaluate the sufficiency of the existing structure if the building were to be developed as a restaurant and to identify the potential areas that may require strengthening. "Commentary L" of the NBCC [3] requires that in the evaluation of an existing structure, when public life safety is involved, the structural integrity of the building be checked 
with respect to the ability of the structure to provide alternative load paths in the case of a local failure, such as losing a column due to an accident, overloading, deterioration, etc. This criterion was checked in the structural analysis of the building and effect of the most severe local failure (losing a corner column) was added to the results of other load combinations. Examples of the axial forces and bending moments due to some load combinations are shown in Figure 9.

The following conclusions can be drawn based on the results of the structural analysis:

1- Cross Beams: In general, the middle two-thirds of the concrete cross beams can resist the applied loads in their original form although the existing transverse reinforcement of the beams does not satisfy current minimum code requirements. More attention has to be paid to the joints between the beams and the columns (item 3 below).

2- Columns: The columns are slender and in a sway frame. Based on the site inspections, they do not satisfy minimum code requirements for transverse reinforcement (ties). They are subject to a maximum combined axial load of $170 \mathrm{kN}$ compressive load and $21 \mathrm{kN}-\mathrm{m}$ bending moment. In some extreme cases, the column can be subjected to $120 \mathrm{kN}$ tensile force (uplift) combined with $23 \mathrm{kN}-\mathrm{m}$ bending moment.
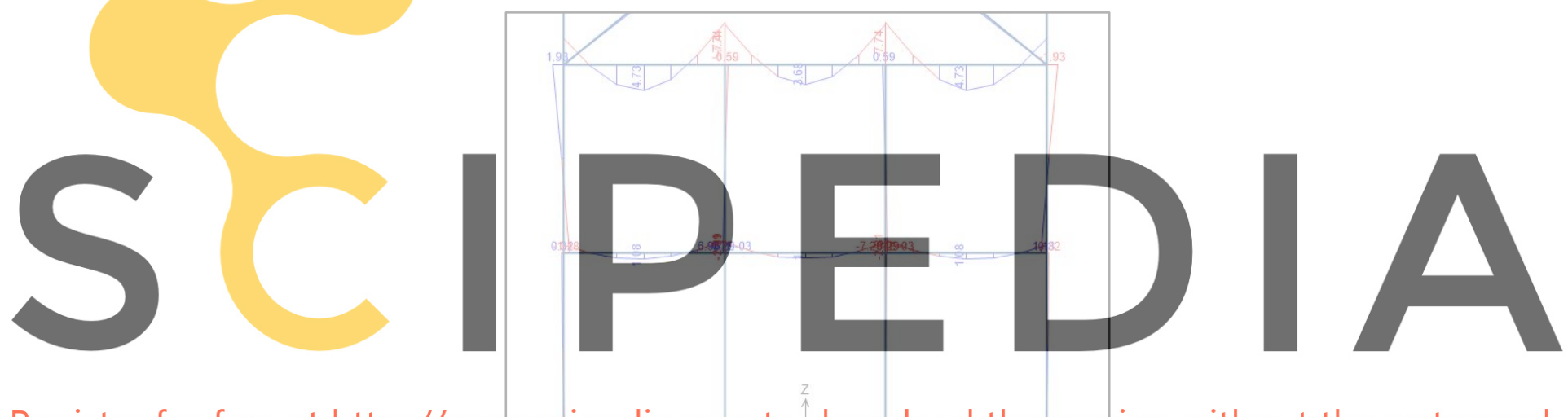

Register for free at https//www.scipedia.com to download the version without the watermark

Figure 9: Bending moment in members due to applied vertical loads (Max=10 kN-m)

3- Beam-column connections: the details of the reinforcement in the beam-column joint areas are not clear, but based on visual site inspections, it is almost certain that the code requirements for beam-column joints in a moment frame are not satisfied.

Because life safety is involved if the building is re-used as a restaurant, and to make sure that the structure can resist the loads adequately, attention has to be paid to existing uncertainties such as the quality of the concrete, the existence and size of steel rebars and stirrups, and the adequacy of rebar splice lengths.

\subsection{STRUCTURAL EVALUATION BASED ON CURRENT USE (SCENARIO 2)}

In the case of keeping the current use of the structure, the occupancy of the building will not change from its current state, and future loads will be similar to past loads and even less than 
the loads applied during operation of the building. In this case, public life safety is also not involved, and because of the lower reliability level of the building, more relaxation in the load combinations is allowed based on Commentary "L" of the NBCC [3]. In this case, the live load on the main floor is reduced to $2 \mathrm{kPa}$, with no superimposed dead load. Also due to the existence of large openings in the walls, the applied basic wind load is less than the loads in scenario 1.

Based on the results of structural analysis and the section properties of the concrete members, and due to satisfactory past performance of the building under similar or higher loads for more than 100 years, according to Commentary "L" of the NBCC [3], no further strengthening other than repairing the deteriorated members to their original shape and protecting them from further deterioration is required for this case. Thus, the damaged beams and columns should just be repaired with compatible and durable material, and a coating applied to protect them from the ingress of water and other damaging materials as well as freeze-thaw cycles. Accumulation of water has to be avoided in the top of the beams, the bottoms of columns, footings and other susceptible areas by providing proper slopes and drainage systems.

\section{SELECTION OF REPAIR AND STRENGTHENING METHODS}

For Scenario 1, strengthening is required. Several repair and strengthening techniques have been used to strengthen concrete moment frame structures. Some of the "traditional" techniques are steel or concrete jacketing, prestressing and the use of external steel plates. Most of the "traditional" techniques are highly intrusive, expensive and involve heavy equipment. High strength composite mat the concrete mémber pro These materials bond can be used to strengther

1- Concrete beanis

2- Concrete column terials such as Fibre Rq
provide a good alternativ
the existing structure
and one-way slabs in flex
ins by wrapping and conf pinforced Polyme
ve for the streng
se and perform as
lexure and shear

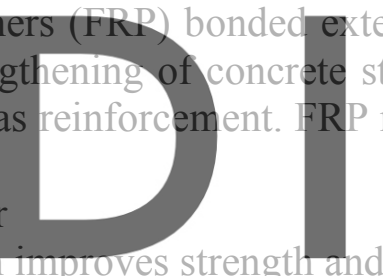
ternally to
structures.
materials Prestressed concrete beams

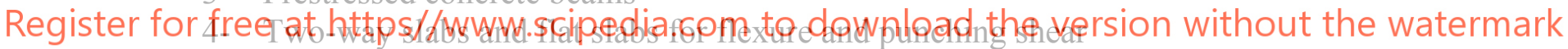

5- Beam-column connections by improving ductility and shear strength

In recent years, high modulus Carbon FRP materials with a modulus of elasticity of more than $200 \mathrm{GPa}$ have become available for use in the construction industry. These materials are thin, lightweight and easy to install using adhesives.

The performance of FRP strengthening of concrete structures depends on two main elements:

1- The durability and performance of the bond between the FRP laminate and the concrete substrate

2- The durability and performance of the FRP material itself.

It is well known that the interface or bond between the FRP and the substrate materials such as concrete can be the weak link when failures occur. Several standard tests have been developed over time to study the durability of the bond between FRP and concrete. Among them are pull-off tests, pull-apart/push-apart shear tests, peel tests, flexural tests, torque tests, 
pull-out tests as well as non-destructive tests such as impact-echo and infrared thermography. The following factors can influence the bond between FRP and concrete [8]:

1- Exposure to moisture

2- High Temperature

3- Freeze-Thaw Conditions

4- Saline and Alkaline Environment

Error! Reference source not found. shows the main characteristics of three different fibre types used in FRP composites.

Table 1: Comparison of the three main types of FRP [9]

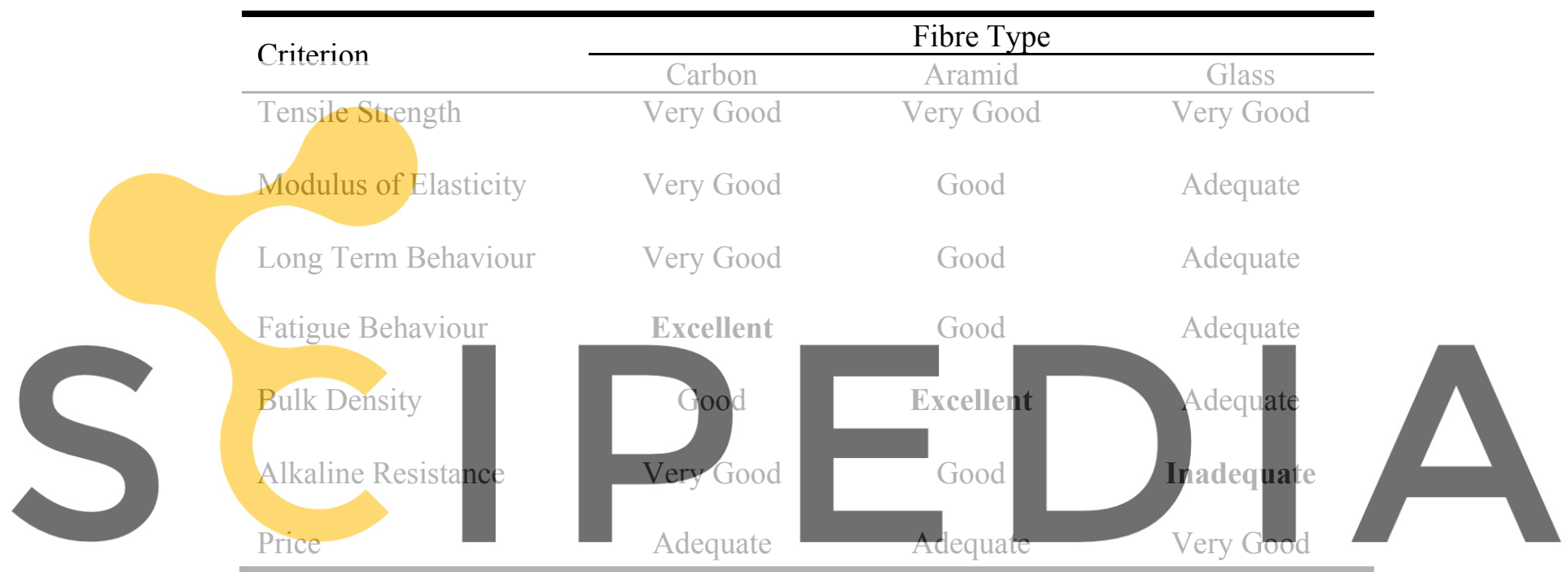

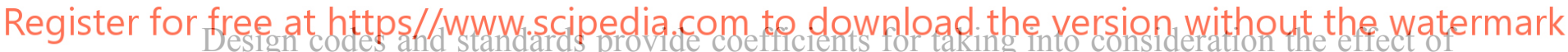
different factors such as environmental effects, type of material and their application. The Canadian Highway Bridge Design Code (CSA-S6-14 2014) [5] and CSA-S806 (CSA S806-12 2012) [4] have also provided resistance factors for the calculation of FRP composite resistance.

\subsection{STRENGTHENING USING FRP COMPOSITES}

In recent decades, different codes, standards and guidelines are published to regulate the use of FRP composites in design and strengthening of structures. In Canada, two codes, CSA S806 [4] and CSA S06 [5], have provisions for the use of FRP in buildings and bridges respectively.

According to CAN/CSA-S806-12[4], before using any FRP strengthening method, an assessment of the current situation of the existing structure or elements should be conducted to assess the current condition of the existing structure and find out the main causes of damage and deterioration. The effects of the applied loads and the capacity of the structure should be calculated. The possibility and feasibility of using FRP strengthening systems such as Externally Bonded or Near-Surface Mounted FRP systems can then be evaluated. 


\subsection{STRENGTHENING OF THE BEAMS FOR FLEXURE AND SHEAR}

The cross beams are $300 \times 300 \mathrm{~mm}$ square concrete reinforced with $2 \times 20 \mathrm{M}$ longitudinal rebars at the top and bottom and $10 \mathrm{~mm}$ stirrups at every $600 \mathrm{~mm}$. The size and spacing of the rebars and stirrups were obtained from inspection of exposed areas. Some beams, especially exterior beams, have suffered from extensive spalling and delamination of the concrete primarily due to freeze-thaw cycles, but section losses in the reinforcing bars of the beams are not significant and usually consist of minor surface corrosion.

If extra resistance for shear and bending moment in the beams are required, the Canadian code S806-12 has provided methods for strengthening using externally-bonded FRP. Schematic views of beam flexural and shear strengthening are shown in Figure 10 and Figure .

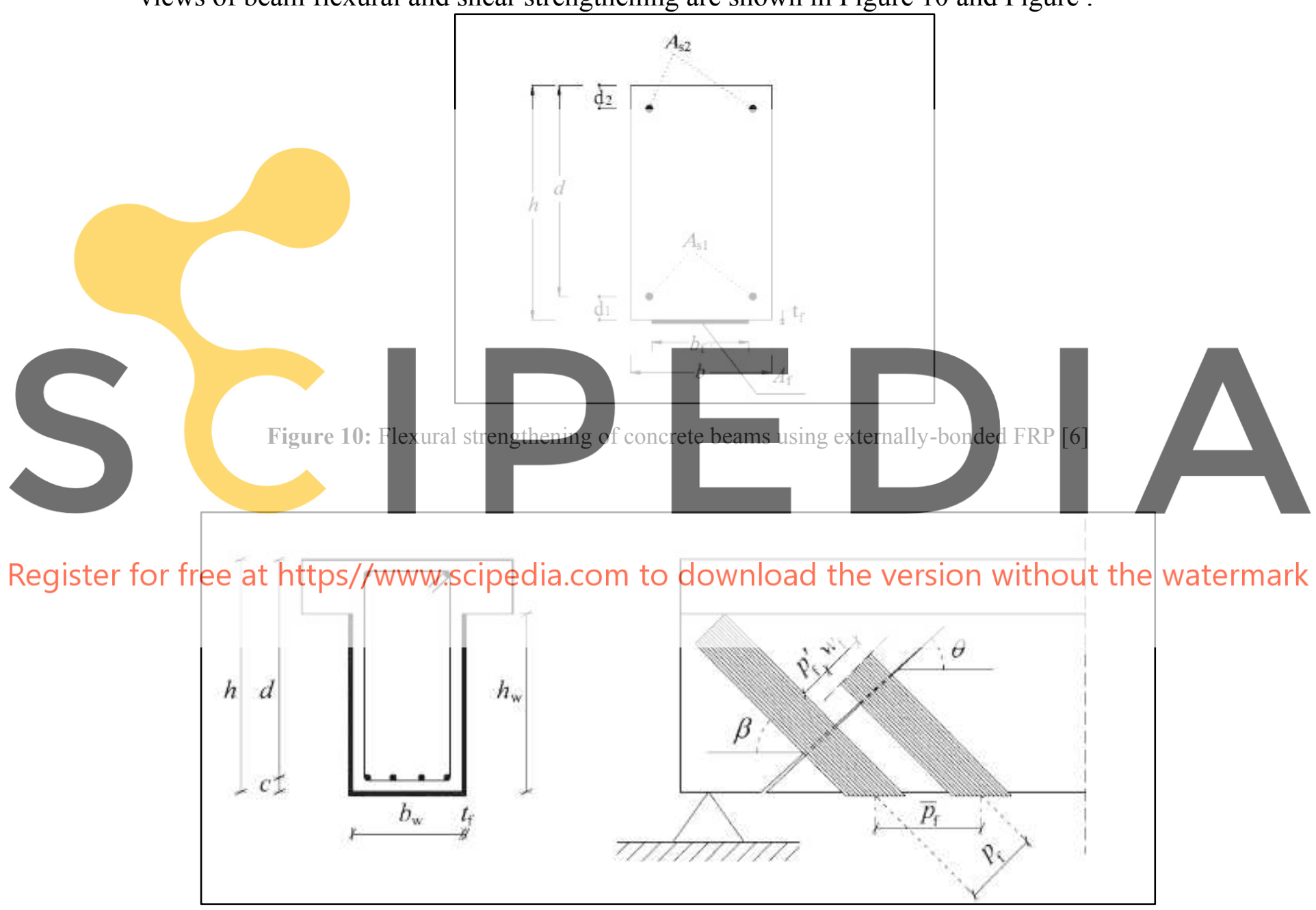

Figure 11: Shear strengthening of concrete beams using externally-bonded FRP [6]

In the FRP flexural and shear strengthening systems, stresses transfer from the FRP to the concrete through the adhesive and these systems are bond-critical applications. Therefore, it is necessary to have appropriate surface preparation and sufficient concrete strength to reach the required strengthening. 


\subsection{STRENGTHENING OF THE COLUMNS}

Confining concrete columns with externally-bonded FRP (EB-FRP) wraps is an effective way to improve the behaviour of concrete columns in several ways such as increasing column axial load capacity, preventing buckling of reinforcement bars, reducing the lap length required for the rebars, and reducing the rate of water ingress into concrete which slows the rate of steel corrosion (Figure ). FRP wrapping also improves the ductility of the member which is beneficial in the dynamic and seismic response of the structure.

Along with several national and international codes from around the world, Canadian codes ("S6-06: Canadian Highway Bridge Design Code" and "S806-12: Design and construction of building structures with fibre-reinforced polymers") have provided methods and formulas for the calculation of the compressive strength of confined members with composite materials.

Given the new occupancy and loadings and existence of uncertainties in quantity and quality of concrete and rebars in the members, and to satisfy the life safety requirement in respect of the reuse of the structure, it would be preferable to strengthen the columns and make sure about the structural stability and integrity of the tipple building. It can be observed that confinement by FRP wraps can theoretically increase the compressive strength of the concrete in the columns from 15 to $20.7 \mathrm{MPa}$. The compressive strength of the columns could be further increased by circularization of the existing rectangular-shaped columns which will increase the effectiveness of confinement by FRP wraps.

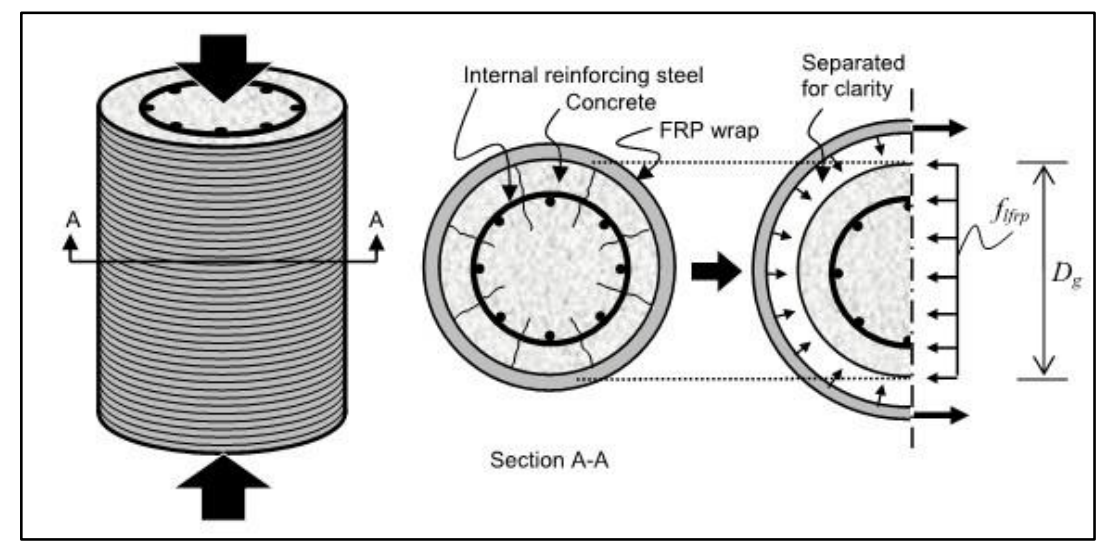

Figure 12: Confinement mechanism for the axial strengthening of circular concrete columns using externally bonded FRP wraps [7]

\subsection{STRENGTHENING OF OTHER MEMBERS}

Other members of the structure such as the concrete slab and the beam-column connections can also be strengthened using externally-bonded FRP wraps.

\section{CONCLUSION}

The Greenhill mine tipple structure is a Provincial historic site and was assessed by field and laboratory tests together with computer modelling to evaluate the current state of the structure and to recommend interventions to ensure the adequacy of the building to resist the loading 
from possible adaptive reuse as a restaurant or maintained as a monument.

The structure was built before knowledge of some critical issues in the design and construction of reinforced concrete structures had been gained, such as the need for adequate concrete cover, durability requirements, freeze-thaw resistance, the need for adequate transverse rebars in beams and columns, proper design and detailing of beam-column joints in moment resisting frames, splice and development lengths of rebars, etc. As a result, damage and deterioration have happened to the structure with freeze-thaw damage being one of the most important ones.

Lack of knowledge about concrete composition and proper grading of the aggregate has resulted in the existence of very large particles in the concrete. It looks like the contractor used ungraded gravel from the nearby river as the aggregate source.

Externally bonded FRPs are recommended for strengthening of different parts of the structure because of their several advantages such as durability, ease of use, lightweight, reversibility and minimum intervention. In the design of the strengthening systems, the existence of several uncertainties about the quality of concrete and aggregates, position, size, cover and splice lengths of longitudinal reinforcing bars, amount of damage and deterioration in different areas, and life safety involvement in the new proposed use of the structure have to be considered.

Acknowledgements. The authors gratefully acknowledge the support of Alberta Culture in providing access to the site and their archives. The University of Calgary provided substantial support through their computing resources and the Department of Civil Engineering, all of which is sincerely acknowledged.

\section{REFERENCES}

[1] G. Associates. Structural Review of Greenhill Mine (2013).

[2] American Concrete Institute. ACI 562-16, Code requirements for assessment, repair, and rehabilitation of existing concrete structures (2016).

[3] CSA Group. National Building Code of Canada (2015).

[4] CSA Group. CSA S806-12, Design and Construction of Building Components with Fibre-Reinforced Polymers (2012).

[5] CAN/CSA-S6-14, Canadian Highway Bridge Design Code (2014), vol. 1, no. 1.

[6] ISIS Canada. FRP Rehabilitation of Reinforced Concrete Structures FRP Rehabilitation of Reinforced Concrete Structures, Design Manual No. 4. (2008).

[7] Banthia N. et al. ISIS Educational Module 4: An Introduction to FRP Composites for Construction (2010). ISIS Canada Educational Module.

[8] Bisby, L. ISIS educational module 8: Durability of FRP Composites for Construction (2006), p. 22.

[9] Banthia N. et al. ISIS Educational Module 2: An Introduction to FRP Composites for Construction. ISIS Canada Educational Module. ISIS Canada (2006), pp. 1-54. 